\title{
Complete sequence of the RNA1 of an European isolate of tomato chlorosis virus
}

\author{
Annotated Sequence Record \\ G. Lozano, E. Moriones and J. Navas-Castillo \\ Estación Experimental La Mayora, Consejo Superior de Investigaciones Científicas, \\ Algarrobo-Costa, Málaga, Spain
}

\section{Introduction}

Tomato chlorosis virus (ToCV, genus Crinivirus, family Closteroviridae) is the causal agent of a "yellow leaf disorder" of tomato (Solanum lycopersicum L.) that is present in Florida at least since 1989 [6]. Nowadays, the presence of ToCV has been confirmed in many countries of the Caribbean, the Far East, southern Africa, and northern and southern sides of the Mediterranean Basin. In Spain, ToCV has been present in tomato since at least 1997 [3] and also has been reported to infect sweet pepper (Capsicum annuum L.) [1]. ToCV is a typical crinivirus with a bipartite genome (RNA1 and RNA2) of single-stranded RNA of positive polarity. Recently, the complete nucleotide sequence of RNA1 and RNA2 of a ToCV isolate from Florida [5], and of RNA2 of an isolate from Spain (AT80/99) [2], have been reported. The sequence of the RNA1 of isolate AT80/99 reported here completes the genomic sequence of an European isolate of ToCV. 


\section{Provenance of the virus material}

Isolate AT80/99 of ToCV was obtained during 1999 from a naturally infected tomato plant from Málaga (southern Spain) and was maintained in tomato cv. Moneymaker by periodic transmission using the whitefly Bemisia tabaci (Q biotype) as vector. Total RNA or double stranded RNA-enriched preparations from infected tomato plants were used in RT-PCR reactions to clone and sequence the RNA1 of isolate AT80/99 following a strategy similar to that used for the RNA 2 [2]. The sequence obtained has been deposited in the GenBank database under the accession number DQ983480.

\section{Sequence properties}

The sequence of ToCV RNA1, isolate AT80/99 consistes of 8,594 nucleotides (nt) and contains four open reading frames (ORFs) (Fig. 1). The first two ORFs encode proteins involved in replication of viral RNA based on homology to other proteins of criniviruses. ORF 1a extends from nt 302 to 6139, and encodes a $221 \mathrm{kDa}$ protein containing protease, methyltransferase, and helicase (Pro-MT-Hel) domains, conserved in all members of the family Closteroviridae. ORF 1b, from nt 6141 to 7655, encodes a $59 \mathrm{kDa}$ protein containing the conserved motifs identified in the RNA dependent RNA polymerases (RdRp) of positive-strand RNA viruses. ORF $1 \mathrm{~b}$ is supposed to be expressed through a +1 ribosomal frame-shift at the end of ORF 1a, as suggested for other closteroviruses. ORF 2, from nt 7662 to 8243, encodes a putative $22 \mathrm{kDa}$ protein of unknown function. The predicted small ORF 3, from nt 8263 to 8418, encodes a putative protein of $6 \mathrm{kDa}$ with a transmembrane domain similar to other 3'-end proteins of criniviruses. In addition to these four ORFs, RNA1 contains a 301 nt 5'-untranslated region (UTR) and a $176 \mathrm{nt}$ 3'-UTR. Overall, the sequence of the RNA1 of isolate AT80/99 from Spain has a nucleotide sequence identity of $97 \%$ with the equivalent RNA of an isolate of Florida recently reported [5]. Table 1 shows the percentages of nucleotide and aminoacid identity of ORFs of the AT80/99 isolate compared with homologous ORFs of the Florida isolate of ToCV and all the crinivirus species sequenced to date. Phylogenetic analysis of the ORFs 1a+1b of isolate AT80/99 (Fig. 2) confirmed the possition of ToCV in the genus Crinivirus, most similar to SPCSV and CYSDV, and closely related to the ToCV isolate from Florida.

\section{Acknowledgements}


This research was funded by grants AGL2001-0542 and AGL2004-06959-C04-01/AGR (Plan Nacional de I + D + I, Spain). G.L. is recipient of a FPI fellowship from the Ministerio de Educación y Ciencia, Spain. We are grateful to Elisa Ruiz and Juan Francisco Campos for technical assistance.

\section{References}

1. Lozano G, Moriones E, Navas-Castillo J (2003) First report of sweet pepper (Capsicum annuum) as a natural host plant for Tomato chlorosis virus. Plant Dis 88: 224

2. Lozano G, Moriones E, Navas-Castillo J (2006) Complete nucleotide sequence of the RNA2 of the crinivirus tomato chlorosis virus. Arch Virol 151: 581-587

3. Navas-Castillo J, Camero R, Bueno M, Moriones E (2000) Severe yellowing outbreaks in tomato in Spain associated with infections of Tomato chlorosis virus. Plant Dis 84: 835-837

4. Thompson JD, Gibson TJ, Plewniak F, Jeanmougin F, Higgins DG (1997) The CLUSTAL X window interface: flexible strategies for multiple sequence alignment aided by quality analysis tools. Nucleic Acids Res 24: 4876-4882

5. Wintermantel WM, Wisler GC, Anchieta AG, Liu H-Y, Karasev AV, Tzanetakis IE (2005) The complete nucleotide sequence and genome organization of tomato chlorosis virus. Arch Virol 150: 2287-2298

6. Wisler GC, Li RH, Liu H-Y, Lowry DS, Duffus JE (1998) Tomato chlorosis virus: a new whitefly-transmitted, phloem-limited, bipartite closterovirus of tomato. Phytopathology 88: 402-409

Author’s address: Jesús Navas-Castillo, Estación Experimental La Mayora, CSIC, 29750 Algarrobo-Costa, Málaga, Spain; e-mail: jnavas@eelm.csic.es 
Table 1. Percentage nucleotide and amino acid (in parenthesis) identities between the putative proteins encoded by the ToCV (isolate AT80/99 from Spain) ORFs compared to equivalent ORFs of the ToCV isolate from Florida and other species in the genus Crinivirus.

\begin{tabular}{lllll}
\hline \multirow{5}{*}{ Virus } & \multicolumn{4}{l}{ ORFs (putative proteins) } \\
\cline { 2 - 5 } & ORF1a & ORF1b & ORF2 & ORF3 \\
\hline ToCV (Florida) & $97(97)$ & $98(99)$ & $96(96)$ & $98(100)$ \\
SPCSV & $50(38)$ & $64(66)$ & $38(14)$ & $34(15)$ \\
CYSDV & $49(33)$ & $63(62)$ & $35(12)$ & $26(18)$ \\
PYVV & $46(33)$ & $61(60)$ & - & $31(14)$ \\
BYVaV & $50(37)$ & $63(62)$ & - & - \\
SPaV & $48(35)$ & $60(58)$ & - & - \\
BPYV-str & $50(36)$ & $63(60)$ & - & $34(16)$ \\
BPYV-cuc & $50(36)$ & $64(62)$ & - & - \\
LIYV & $48(29)$ & $57(55)$ & $29(10)$ & - \\
\hline
\end{tabular}




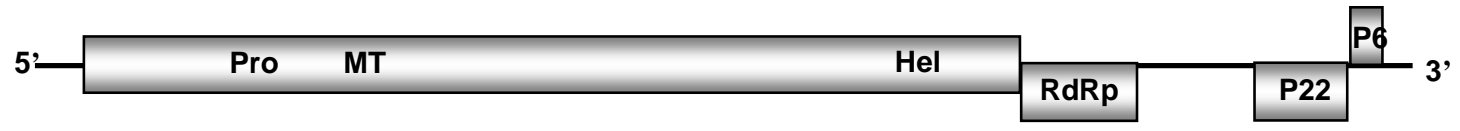

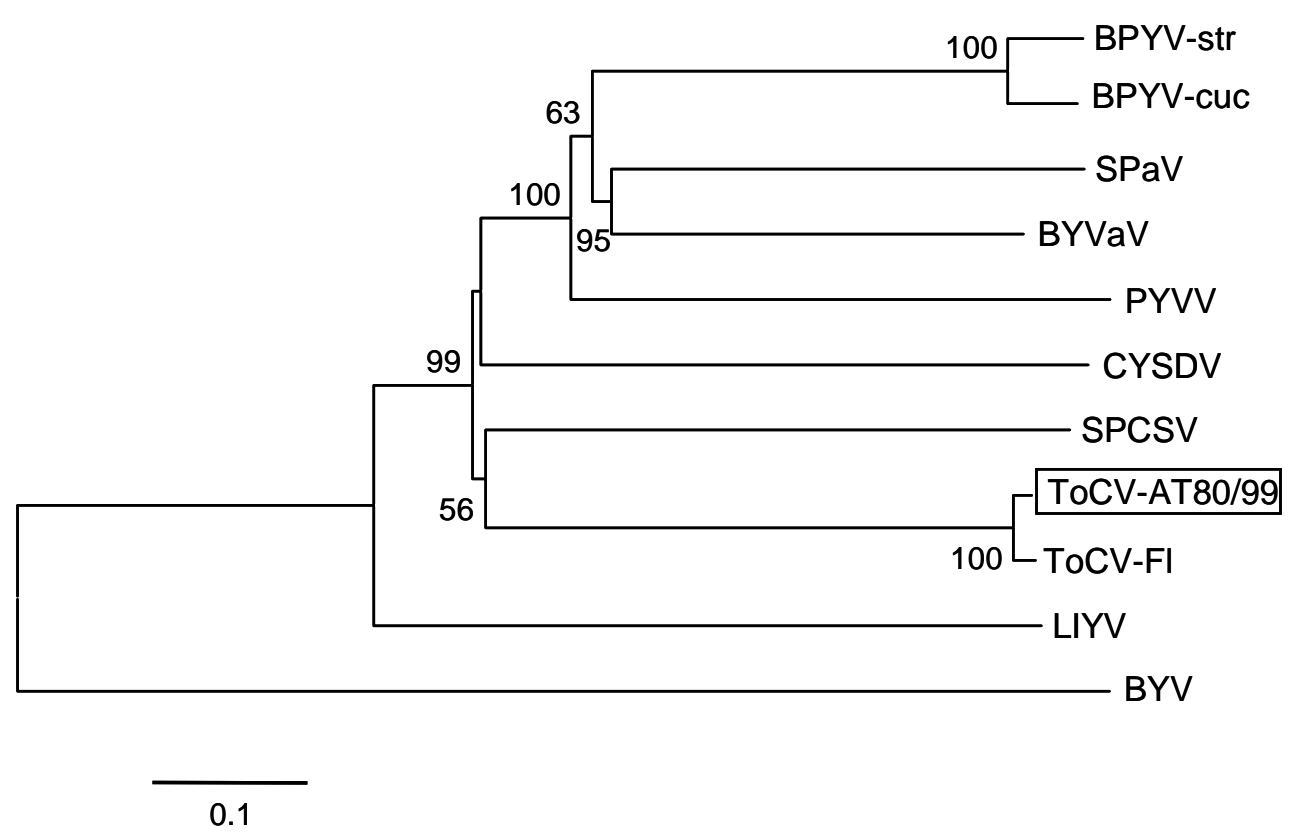




\section{FIGURE LEGENDS}

Fig. 1. Schematic representation of the genomic structure of the RNA1 of the Spanish isolate AT80/99 of ToCV. Boxes represent ORFs, with the putative protein products indicated inside.

Fig. 2. Phylogenetic relationship of ToCV (isolate AT80/99) ORFs $1 \mathrm{a}+1 \mathrm{~b}$, with the corresponding genomic regions of sequenced members of the genus Crinivirus. Abbreviations and GenBank accession numbers: BPYV-cuc, beet pseudo-yellows virus (“cucumber yellows” strain), AB085612; BPYV-str, beet pseudo-yellows virus ("strawberry” strain), AY330918; BYVaV, blackberry yellow vein associated virus, AY776334; CYSDV, cucurbit yellow stunting disorder virus, AY242077; LIYV, lettuce infectious yellows virus, U15440; PYVV, potato yellow vein virus, AJ557128; SPaV, strawberry pallidosis associated virus, AY488137; SPCSV, sweet potato chlorotic stunt virus, AJ428554; ToCV-Fl, tomato chlorosis virus ("Florida” isolate), AY903447. Beet yellows virus (BYV, type species of the genus Closterovirus) (X73476) was used as outgroup. Phylogenetic tree was constructed using the CLUSTAL X program [4]. Bootstrap (1000 replicates) values are shown as percentage value and only the nodes over $50 \%$ are labeled. The bar below the tree indicates 0.1 nucleotides substitutions per site. 